\title{
FAKTOR YANG MEMPENGARUHI PENEMUAN KASUS PNEUMONIA BALITA DI WILAYAH KERJA UPTD PUSKESMAS PAMMANA
}

\section{Factors that affecting the discovery of pneumina case in toodlers at working area of UPTD Puskesmas Pamamana}

\author{
Fitriani, Amal Hayati, Yulianti \\ Puskesmas Pammana Kabupaten Wajo \\ fitrianiskm15@yahoo.co.id
}

\begin{abstract}
Pneumonia is an inflammation of the lung parenchyma that can affect anyone, such as children, adolescents,young adults and the elderly,but more in infants. Based on data from the health profile of South Sulawesi province,Wajo Regency is in the top 10, namely the 7th highest ranking with the detection of pneumonia cases in children under five who were treated at $0.15 \%$ from 23 Puskesmas in Wajo Regency while in Pammana Puskesmas from Years 2016-2019 the number of pneumonia sufferers is fluctuating where the data obtained only comes from patient visits to the Puskesmas. This is still far from the estimated target of pneumonia cases in children under five, which is $10 \%$ of the total population in the working area.This study aims to determine the factors that influence infant pneumonia case finding at Pammana Health Center,Wajo.This research is a descriptive epidemiological mixed methods approach (qualitative and quantitative) with a case study design. Informants in this study was the head of the clinic,person in charge of P2 ISPA program IMCI officer and expert informants.Data collected by interview,observation and document review conducted in Puskesmas Pammana. Results showed that the factors that influence the discovery of pneumonia cases in toddlers at the public health center are programming, activities program, recording and reporting, health workers factors (training,knowledge, and working time), motivation, the head public health center's leadership, availability of print and reach media. While the factors that do not affect the discovery of pneumonia cases are gender, education level,management of $\mathrm{IMCl}$ and activies evaluation. The conclusion is, in order to th coverage of pneumonia cases in toodlers at Puskesmas Pammana the target, it can be done by improving guidance and training to the person in charge of P2 ISPA and IMCI officer on toddler pneumonia knowledge.PHC also need to conduct a finding case actively by doing cases tracking and visit the home of the toddlers who is suffering from pneumonia.
\end{abstract}

Keywords : ISPA, Puskesmas, Toodler pneumonia

\section{ABSTRAK}

Pneumonia adalah peradangan pada parenkim paru dapat menyerang siapa aja, seperti anak-anak, remaja, dewasa muda dan lanjut usia, namun lebih banyak pada balita dan lanjut usia. Berdasarkan data profil kesehatan provinsi sulawesi selatan, Kabupaten Wajo masuk dalam 10 besar yaitu peringkat ke 7 tertinggi dengan penemuan kasus pneumonia pada balita yang ditangani sebesar $0,15 \%$ (359 Penderita) dari 23 Puskesmas yang ada di Kabupaten Wajo sedangkan di Puskesmas Pammana dari Tahun 2016 - 2019 jumlah penderita Pneumonia bersifat fluktuatif dimana data yang di peroleh hanya berasal dari kunjungan penderita ke Puskesmas. Hal ini masih jauh dari target perkiraan kasus pneumonia pada balita yaitu sebesar $10 \%$ dari jumlah penduduk di wilayah kerja. Penelitian ini bertujuan untuk mengetahui faktor yang mempengaruhi pnemuan kasus pneumonia balita di Puskesmas Pammana, Kabupaten Wajo.Penelitian ini merupakan penelitian epidemiologi deskriptif dengan pendekatan mixed methods (kualitatif dan kuantitatif). Informan dalam penelitian ini adalah kepala puskesmas, penanggung jawab program P2 ISPA dan petugas MTBS serta informan ahli. Pengumpulan data dilakukan dengan wawancara mendalam, observasi dan telaah dokumen yang dilakukan di Puskesmas Pammana. Hasil penelitian ini menunjukkan bahwa faktor-faktor yang mempengaruhi penemuan kasus pneumonia balita di puskesmas pammana yaitu penyusunan rencana program, kegiatan program, pencatatan dan pelaporan, faktor petugas kesehatan (pelatihan, pengetahuan, dan lama kerja petugas), motivasi kerja, kepemimpinan kepala puskesmas, ketersediaan media cetak dan media penyuluhan. Sedangkan faktor yang tidak berpengaruh dengan penemuan kasus pneumonia yaitu jenis kelamin, tingkat pendidikan, tatalaksana MTBS dan kegiatan evaluasi. Kesimpulan agar cakupan penemuan kasus pneumonia balita di Puskesmas pammana mencapai target, dapat dilakukan dengan meningkatkan pembinaan dan pelatihan kepada penanggung jawab P2 ISPA dan petugas MTBS mengenai pengetahuan pneumonia balita. Puskesmas juga perlu melakukan kegiatan penemuan kasus secara aktif dengan melakukan pelacakan kasus dan kunjungan rumah penderita pneumonia balita.

Kata Kunci: ISPA, Puskesmas, Pneumonia Balita

Vol. XV No. 2, Desember 2020 


\section{PENDAHULUAN}

Pneumonia balita adalah penyakit yang menyerang jaringan paru-paru dan atau ditandai dengan batuk dan kesulitan bernapas, yang biasa disebut sebagai napas cepat atau sesak napas pada anak usia balita. Pneumonia merupakan penyakit batuk pilek disertai napas cepat. 1 Proporsi pneumonia balita di Indonesia dari pada tahun 2008 adalah 49,45\%, tahun 2009 adalah $49,23 \%$ dan tahun 2010 adalah $39,38 \%$ dari jumlah balita di Indonesia. Rata-rata insidens pneumonia nasional dari tahun 2001 sampai 2010 berada pada daerah kuning atau daerah yang memiliki insidens rate antara 1-4 per 100.000 penduduk dan termasuk kategori sedang, hanya pada tahun 2001 dan 2004 pernah berada di kategori merah atau daerah yang memiliki insidens rate lebih dari $>4$ per 100.000 penduduk dan termasuk kategori tinggi.

Menurut Profil Kesehatan Indonesia, pneumonia menyebabkan 15 persen kematian balita yaitu sekitar 922.000 balita tahun 2015. Dari tahun 2015-2018 kasus pneumonia yang terkonfimasi pada anakanak dibawah 5 tahun meningkat sekitar 500.000 per tahun. Tercatat jumlah penderita radang paru tersebut mencapai 505.331 pasien dengan 425 pasien meninggal.

Banyak faktor yang berkontribusi terhadap kejadian pneumonia, dan tidak ada intervensi tunggal yang secara efektif dapat mencegah, mengobati dan mengendalikan. Adapun intervensi sederhana namun efektif jika dilaksanakan secara tepat, yang dapat menurunkan beban penyakit ini yaitu : a. Lindungi ( Protect ) b. Cegah ( Prevent ) c. Obati ( Treat). Pada tahun 2016 jumlah perkiraan penderita kasus pneumonia pada balita sebesar 6.511.572 kasus dan jumlah balita penderita pneumonia yang ditemukan dan ditangani sebanyak $6.288 \quad(0,10 \%)$. Sedangkan untuk Kabupaten Wajo masuk dalam 10 besar yaitu peringkat ke 7 tertinggi dengan penemuan kasus pneumonia pada balita yang ditangani sebesar $0,15 \%$ (359 Penderita) dari 23 Puskesmas yang ada di Kabupaten Wajo. (Profil kesehatan Provinsi Sulawesi Selatan, 2016).

Berdasarkan data P2 ISPA Puskesmas Pammana Tahun 2016 - 2019 jumlah penderita Pneumonia bersifat fluktuatif dimana dari tahun 2016 (11 kasus) ke tahun 2017 (7 Kasus) terjadi Penurunan.
Kemudian pada tahun 2017 ke tahun 2018 (21 kasus) terjadi peningkatan kasus yang signifikan dan terjadi penurunan kasus kembali pada tahun 2019 (10 Kasus). Penderita Pneumonia yang tercatat dalam program P2 ISPA didapatkan dari kunjungan penderita ke Puskesmas. Hal ini masih jauh dari target perkiraan kasus pneumonia pada balita yaitu sebesar $10 \%$ dari jumlah penduduk di wilayah kerja. Untuk mencapai target penemuan kasus pneumonia, diperluhkan berbagai upaya, seperti Penemuan kasus dilaksanakan melalui kegiatan yang menunjang upaya masyarakat untuk mencari pengobatan kasus pneumonia secara tepat dan deteksi dini oleh petugas kesehatan. Selain itu perlu dilakukan dan dioptimalkan penemuan dan tatalaksana penderita di rumah tangga dan masyarakat (keluarga, kader, dan Posyandu di tingkat pelayanan kesehatan tingkat pertama atau dasar (Puskesmas pembantu dan pelayanan kesehatan di desa) dan disarana kesehatan rujukan (Rumah Sakit) (Kemenkes, 2012).

Tujuan Penelitian ini adalah:

1. Tujuan Umum

Mengetahui faktor yang mempengaruhi penemuan kasus pneumonia balita di Puskesmas Pammana Tahun 2020

2. Tujuan Khusus

a. Mengetahui penemuan kasus pneumonia balita di Puskesmas Pammana Tahun 2017 - 2019

b. Mengetahui perencanaan kegiatan penemuan kasus pneumonia balita di Puskesmas Pammana Tahun $2017-2019$

c. Mengetahui kegiatan penemuan kasus pneumonia balita di Puskesmas Pammana Tahun 2017 $-2019$

d. Mengetahui kegiatan pencatatan dan pelaporan kasus pneumonia balita di Puskesmas Pammana Tahun 2017 - 2019

e. Mengetahui kegiatan tatalaksana penemuan kasus pneumonia balita di Puskesmas Pammana Tahun $2017-2019$

f. Mengetahui faktor petugas kesehatan (jenis kelamin petugas, pelatihan petugas, pendidikan Petugas, lama memegang program P2 ISPA, pengetahuan petugas, motivasi petugas dan kepemimpinan kepala puskesmas) dalam kegiatan pelaksanaan 
penemuan kasus pneumonia balita di Puskesmas Pammana Tahun $2017-2019$

g. Diketahuinya faktor motivasi mempengaruhi penemuan kasus pneumonia balita di Puskesmas Pammana Tahun 2017 - 2019

h. Diketahuinya faktor kepemimpinan kepala Puskesmas yang mempengaruhi cakupan penemuan kasus pneumonia balita di Puskesmas Pammana Tahun $2017-2019$

i. Mengetahui ketersediaan sarana dan prasarana (media cetak/buku cetakan dan media penyuluhan) dalam kegiatan pelaksanaan penemuan kasus pneumonia balita di Puskesmas Pammana Tahun $2017-2019$

j. Mengetahui kegiatan evaluasi dalam kegiatan pelaksanaan penemuan kasus pneumonia balita di Puskesmas Pammana Tahun $2017-2019$

\section{METODE DAN SUBJEK PENELITIAN}

Penelitian ini merupakan penelitian epidemiologi deskriptif dengan pendekatan mixed methods (kualitatif dan kuantitatif) dilakukan dengan menggunakan beberapa metode dalam melakukan pengumpulan data diantaranya wawancara mendalam, observasi dan telaah data sekunder berupa dokumen-dokumen terkait penemuan penderita pneumonia balita. Informan dalam penelitian ini adalah kepala puskesmas, penanggung jawab program P2 ISPA dan petugas MTBS serta informan ahli.

Data hasil wawancara dan observasi serta telaah dokumen dianalisis secara deskriptif untuk mendapatkan gambaran suatu keadaan sebenarnya kemudian dibandingkan dengan keadaan yang seharusnya.

Teknik analisis data dalam penelitian ini menggunakan analisis isi (content analysis). Menurut Holsti (1969) dalam Moleong (2009), analisis isi merupakan suatu teknik penelitian untuk menarik kesimpulan dengan mengidentifikasi karakteristik khusus suatu pesan objektif dan sistematik. Sesuai dengan penjelasan teknik analisis data kualitatif yaitu analisis isi, semua data yang sudah diperoleh selanjutnya dinarasikan dan disusun ke dalam transkrip untuk kemudian dibuat matriksnya. Data yang telah disusun kemudian diidentifikasi faktor mana yang menjadi penyebab masalah dalam penemuan penderita pneumonia balita.

\section{DESAIN, TEMPAT DAN WAKTU}

Jenis penelitian yang digunakan dalam penelitian ini adalah epidemiologi deskriptif pendekatan kualitatif dan kuantitaif dengan desain studi kasus. Studi kasus merupakan penelitian yang berusaha menemukan makna, menyelidiki proses dan memperoleh pengertian yang mendalam tentang individu, satu kelompok, satu organisasi, satu program kegiatan, dan situasi dalam waktu tertentu.

Tempat penelitian dilakukan di UPTD Puskesmas Pammana yang dilakukan selama kurang lebih 2 bulan dimulai sejak bulan Februari 2020.

\section{HASIL}

Karakteristik Informan pada penelitian ini terdiri dari informan utama yaitu kepala Puskesmas dan informan pendukung yaitu penanggung jawab P2 ISPA dan petugas MTBS di Puskesmas Pammana. Selain itu peneliti juga mewawancarai informan ahli untuk memberikan penjelasan mengenai permasalahan dalam penemuan kasus pneumonia balita di Puskesmas Pammana.

Penemuan kasus pneumonia balita di Puskesmas dapat dilihat dari cakupan penemuan kasusnya. Dalam pelaksanaan program P2 ISPA ada beberapa indikator yang dapat digunakan untuk memantau dan menilai pelaksanaan program. Salah satu indikator utama yang digunakan yaitu cakupan penemuan kasus pneumonia. Dalam penelitain ini yang dimaksud cakupan penemuan pneumonia adalah jumlah kasus yang berhasil ditemukan dan dilakukan tindakan tatalaksana penderita. Angka cakupan penemuan kasus pneumonia didapatkan dari hasil pembagian antara jumlah kasus pneumonia yang ditemukan disuatu wilayah kerja Puskesmas selama tahun 2017- 2019 dengan jumlah estimasi kasus pneumonia balita di Wilaya kerja Puskesmas tersebut. Adapun cakupan nasional yang ditetapkan Kemenkes setiap tahunnya sebesar $100 \%$.

\section{PEMBAHASAN}

Dalam penelitian ini, faktor-faktor yang dapat mempengaruhi penemuan kasus pneumonia balita di puskesmas, yang merupakan variabel penelitian adalah perencanaan program, kegiatan program, 
tatalaksana pneumonia balita/MTBS, pencatatan dan pelaporan, motivasi petugas, kepemimpinan kepala puskesmas, ketersediaan sarana dan prasarana serta kegiatan evaluasi. Selain itu, dari segi faktor petugas kesehatan yaitu jenis kelamin, status pelatihan, tingkat pendidikan, lama kerja, pengetahuan tentang konsep pneumonia balita. Berikut ini adalah pembahasan dari hasil penelitian yang telah dilakukan.

1. Perencanaan Program penemuan Kasus Pneumonia Balita

Perencanaan program merupakan suatu rangkaian kegiatan yang disusun secara sistematis untuk mencapai tujuan yang telah ditetapkan/ diputuskan bersama (Herijulianti, dkk, 2002). Dari definisi tersebut dapat disimpulkan, bahwa perencanaan program sangat penting untuk dilakukan.Perencanaan program penemuan pneumonia balita adalah bagian dari program P2 ISPA di puskesmas.

Berdasarkan hasil penelitian, diketahui bahwa pembuatan perencanaan program di Puskesmas pammana dilakukan pada awal setiap tahun berjalan, tepatnya bulan Januari dan Februari. Adapun petugas yang membuatnya adalah penanggung jawab program. Sehingga terkesan belum siap untuk melakukan pelaksanaan program.

Agar program penemuan kasus pneumonia balita mencapai target nasional maka harus menyusun perencanaan program yang dilakukan pada akhir tahun, sehingga kegiatan tersebut dapat dimulai pada awal tahun. Selain itu juga harus bekerjasama dengan petugas puskesmas yaitu Promkes, Kesling, MTBS, dokter dan Binwil. Hasil penelitian dengan pendekatan kuantitaif, yang dilakukan Warsihayati (2002) menunjukkan bahwa pembuatan rencana kerja tahunan memberikan pengaruh terhadap cakupan kasus pneumonia balita disuatu puskesmas.

Sedangkan penelitian Dharoh, dkk (2014) menyebutkan bahwa tidak ada hubungan antara perencanaan program dengan penemuan penderita pneumonia balita. Hal ini terjadi, karena perencanaan dibuat hanya untuk memenuhi kebutuhan Dinas Kesehatan, perencanaan tidak digunakan sebagai acuan pelaksanaan kegiatan.

Tidak berbeda dengan pendapat informan ahli, bahwa perencanaan dalam suatu organisasi harus dibuat untuk mencapai program dengan melibatkan semua staf puskesmas.

2. Kegiatan Program Penemuan kasus Pneumonia Balita

Standar dari Kemenkes (2012) mengenai kegiatan penemuan kasus pneumonia balita di puskesmas dapat dilakukan dengan penemuan kasus pneumonia secara aktif maupun pasif. Penemuan kasus secara aktif dilaksanakan oleh petugas puskesmas dengan mendatangi pasien atau mencari kasus di masyarakat melalui deteksi dini. Sedangkan penemuan kasus secara pasif dilaksanakan diseluruh wilayah kerja puskesmas yang ada, dengan melihat data jumlah penderita yang datang, untuk berobat ke puskesmas tersebut. Kegiatan tersebut berpengaruh terhadap pencapaian target penemuan kasus pneumonia balita di puskesmas

Berdasarkan hasil penelitian, diketahui bahwa kegiatan tersebut hanya dilakukan secara pasif yaitu dengan menunggu pasien datang ke puskesmas, dan hanya melakukan penyuluhan saja di Posyandu, tanpa melakukan deteksi dini atau pencarian kasus pneumonia balita di masyarakat. Selain itu, untuk mencapai target penemuan kasus pneumonia, petugas puskesmas meminta laporan dari kilinik swasta yang ada di wilayah kerja puskesmas tersebut, jika ada kasus pneumonia balita. Informan juga mengakui, bahwa tidak ditemukan kasus pneumonia, tetapi kasus ISPA yang paling banyak ditemukan di puskesmas tersebut. Akibatnya puskesmas kesulitan untuk mencapai target. Hal 150 ini mungkin terjadi, karena kurangnya pengetahuan dan keterampilan petugas mengenai pneumonia balita, sehingga mempengaruhi penemuan kasus.

Penelitian yang dilakukan Handayani (2012) di Puskesmas Kota Semarang menyebutkan bahwa penemuan kasus yang dilakukan 
Puskesmas tersebut adalah penemuan kasus secara pasif hal ini menyebabkan hanya $10 \%$ Puskesmas yang mencapai target nasional. Berbeda dengan hasil penelitian kuantitatif yang dilakukan oleh Dharoh, dkk (2014) menyebutkan bahwa tidak ada hubungan antara pelaksanaan program dengan cakupan penemuan kasus penderita pneumonia balita.

3. Tatalaksana Pneumonia Balita/ MTBS

Pola tatalaksana penderita yang dipakai dalam penanggulangan pneumonia balita didasarkan pada aturan tatalaksana pneumonia yang diterbitkan WHO tahun 1988, dan telah mengalami adaptasi sesuai kondisi Indonesia (Kemenkes, 2012). Pada saat ini tatalaksana pneumonia balita berpedoman pada MTBS di puskesmas. Sehingga semua puskesmas wajib melakukan MTBS, dengan adanya MTBS di puskesmas penyakit pneumonia yang diderita balita dapat diketahui dan segera diatangani oleh petugas yang bewenang.

Tatalaksana pneumonia balita di Puskesmas Pammana dilakukan oleh dokter umum dan dibantu oleh bidan atau perawat. Jika dokter tersebut tidak melakukan pelayanan di puskesmas, maka yang melakukan tatalaksana tersebut adalah bidan dan perawat. Namun, bidan atau perawat di puskesmas tersebut, belum pernah mendapatkan pelatihan atau belum memahami secara detail mengenai pneumonia balita. Akibatnya dalam kegiatan tersebut tidak ditemukan kasus pneumonia balita.

Hal tersebut didukung dengan pernyataan dari informan ahli. Menurut informan ahli pada saat penatalaksanaan pneumonia balita. seharusnya diserahkan kepada yang berwenang yaitu dokter dan 155 petugas yang sudah terlatih dalam tatalaksana pneumonia balita atau MTBS. Sedangkan, untuk penemuan kasus pneumonia balita boleh dilakukan oleh siapa saja yang sudah mendapatkan pengetahuan mengenai pneumonia balita. Dengan demikian untuk petugas Puskesmas diharapkan dapat melaksanakan tatalaksana pneumonia balita atau MTBS sesuai dengan prosedur yang telah ditetapkan Kemenkes, guna untuk menemukan kasus pneumonia balita sedini mungkin di Puskesmas.

\section{Pencatatan dan pelaporan}

Pencatatan dan pelaporan dalam kegiatan penemuan kasus pneumonia balita, mencakup analisis data yang dilakukan berdasarkan kategori kelompok umur. Hal ini dilakukan untuk mempermudah pengambilan kebijakan dalam rangka pengendalian dan pencegahan pneumonia (Kemenkes, 2012). Kegiatan pencatatan dan pelaporan dalam penelitian ini adalah kegiatan pencatatan yang dilakukan oleh P2 ISPA, baik data dari puskesmas maupun klinik swasta.

Berdasarkan hasil penelitian, diketahui bahwa puskesmas pammana telah melakukan pencatatan dan pelaporan. Namun, kasus pneumonia tidak ditemukan di puskesmas tersebut. Hal ini mungkin terjadi, karena petugas di puskesmas tersebut belum mendapatkan pelatihan dan kurang memahami mengenai tatalaksana pneumonia. Sehingga di puskesmas tersebut tidak ada catatan kasus pneumonia. Dengan adanya hal ini, seharusnya penannggung jawab P2 ISPA di Dinkes melakukan supervisi ke puskesmas tersebut. Selain itu, puskesmas tersebut tidak menerima laporan dari klinik swasta mengenai kasus pneumonia, meskipun puskesmas melakukan kegiatan pencarian kasus ke klinik-klinik swasta.

Seharusnya petugas dari Dinkes melakukan pembinaan atau pemantauan untuk mengetahui hambatan apa saja yang ada di puskesmas tersebut. Sehingga pencapaian target penemuan kasus tidak tercapai.

Menurut penelitian kuantitatif yang dilakukan oleh Ningrum (2006), diketahui bahwa petugas yang terlambat dalam melakukan pencatatan dan pelaporan kasus, akan menjadi salah satu faktor penyumbang ketidakberhasilan program di puskesmas. Sedangkan menurut informan ahli kegiatan pencatatan di puskesmas seharusnya tidak dilakukan berkali-kali dan pelaporan dari klinik swasta bersifat sukarela. 
5. Faktor petugas Kesehatan

Dalam penelitian ini faktor petugas kesehatan, yang diteliti yaitu jenis kelamin petugas, pelatihan petugas, pendidikan petugas, lama memegang program dan pengetahuan petugas. Faktor petugas diteliti, karena semua kegiatan dilakukan oleh petugas puskesmas.

a. Jenis Kelamin

Berdasarkan penelitian yang dilakukan di Puskesmas Pammana, di dapatkan bahwa tidak ada hubungan antara jenis kelamin dengan kinerja petugas kesehatan.

Hasil penelitian ini, didukung dengan hasil penelitian Mulyaningsih (2013) menunjukkan bahwa tidak ada hubungan yang bermakna antara jenis kelamin dengan kinerja petugas kesehatan. Perempuan dan laki-laki juga tidak ada perbedaan yang konsisten dalam kemampuan memecahkan masalah, keterampilan analisis, dorongan kompetitif, motivasi dan sosiabilitas dan kemampuan belajar (Rival dan Mulyadi, 2010). Hal ini berbeda dengan pendapat yang disampaikan informan ahli bahwa antara perempuan dan lakilaki dalam melaksanakan tugas ada perbedaannya yaitu laki-laki lebih intens, sedangkan perempuan lebih teliti dalam merawat balita, terutama dalam penemuan kasus pneumonia balita di Puskesmas.

b. Pelatihan Petugas

Puskesmas Pammana tidak mempunyai tenaga terlatih, terutama penanggung jawab P2 ISPA dan petugas MTBS mengakui bahwa belum pernah mendapatkan pelatihan mengenai pneumonia. Hanya ada satu petugas MTBS yaitu dokter umum yang pernah dilatih, akan tetapi petugas tersebut baru 5 bulan menjadi petugas MTBS. Sebelumnya petugas tersebut mendapatkan pelatihan dari dinas kesehatan, ketika bekerja di puskesmas yang dulu.

Hasil penelitian ini, sejalan dengan penelitian kuantitatif yang dilakukan Ivantika (2001) di
Bandung menyatakan bahwa petugas yang telah mendapatkan pelatihan sebelumnya, memiliki peluang 1,353 kali lebih besar untuk mendapat cakupan program yang lebih tinggi dibandingakn dengan petugas yang tidak mendapat pelatihan.

c. Pendidikan petugas

Pendidikan adalah tugas untuk meningkatkan pengetahuan, wawasan, pengertian dan keterampilan dari para personil, sehingga mereka lebih dapat berkualitas (Notoatmodjo, 2003). Dengan adanya pendidikan, seseorang diharapkan menjadi pribadi yang cerdas, kreatif, terampil, disiplin, beretos kerja profesional, bertanggung jawab dan produktif. Menurut Kemenkes (2010), bahwa pengembangan dan peningkatan tenaga kesehatan dilakukan melalui pendidikan dan pelatihan. Dalam penelitian ini yang dimaksud dengan pendidikan petugas adalah pendidikan formal terakhir yang pernah ditempuh oleh petugas pelaksana.

Berdasarkan penelitian yang dilakukan di puskesmas Pammana, pendidikan Petugas P2 ISPA adalah D3 Perawatan.

Hasil penelitian ini sesuai dengan penelitian Handayani (2012), bahwa pendidikan petugas P2 ISPA dan MTBS di Puskesmas yaitu D3 Kebidanan, D3 Keperawatan dan D3 Kesehatan lingkungan. Hasil penelitian ini juga didukung dengan penelitian Ivantika (2001), Sinora (2005) dan Dharoh, dkk (2014) menyatakan bahwa tidak ada hubungan yang bermakna antara 166 pendidikan petugas dengan cakupan penemuan penderita pneumonia. Selain itu, hasil penelitian Duhri, dkk (2013) menyebutkan bahwa petugas P2TB yang memiliki jenjang pendidikan yant tinggi belum tentu memilki kinerja yang baik.

\section{d. Lama Kerja Petugas}

Menurut Wahyudi (2006) pengalaman seorang tenaga kerja 
untuk melakukan suatu pekerjaan tertentu dinyatakan dalam lamanya melaksanakan pekerjaan tersebut. Lama kerja seseorang dalam organisasi perlu diketahui karena lama kerja dapat merupakan salah satu indikator tentang kecenderungan petugas tersebut dari berbagai segi kehidupan organisasional, misalnya dikaitkan dengan produktivitas kerja (Siagian, 2002).

$$
\text { Pada umumnya, semakin }
$$$$
\text { lama orang bekerja maka }
$$
pengalaman bekerjanya akan bertambah luas, sehingga orang tersebut kan menjadi semakin terampil dalam melaksanakan pekerjaanya. Dalam penelitian ini yang dimaksud dengan lama kerja petugas adalah berapa lama penangung jawab P2 ISPA memegang program tersebut sampai dengan waktu diwawancara.

$$
\text { Lama Kerja Petugas P2 }
$$

ISPA masih terbilang baru (1-2 Tahun). Dan setiap tahunnya pemegang program selalu di ganti, sehingga lama kerja mempengaruhi pengalaman kerja dan hasil kinerja.

Hasil Penelitian ini sesuai dengan pendapat Gibson (1987), menyatakan bahwa lama kerja memberikan pengaruh kepada prestasi kerja. Menurut penelitian kuantitatif yang dilakukan oleh Setiadi (2001). ditemukan bahwa terdapat hubungan yang bermakna antara lama kerja dengan kinerja bidan dalam penemuan kasus ISPA. Penelitian ini juga didukung dengan hasil penelitian yang dilakukan Ivantika (2001) menyatakan bahwa ada hubungan yang bermakna antara lama kerja pengelola P2 ISPA dengan cakupan penemuan penderita pneumonia. e. Pengetahuan petugas

Menurut Soekidjo Notoatmodjo (2007) seseorang dikatakan mencapai tingkat pengetahuan yang baik apabila mampu menyebutkan, menguraikan, mendifinisikan, menyatakan dan sebagainya serta menjelaskan secara benar obyek yang telah dipelajari. Dalam penelitian ini yang dimaksud dengan penegatahuan petugas adalah pengetahuan mengenai klasifikasi pneumonia, gejala dan tanda-tanda penderita pneumonia serta tatalaksana penderita pneumonia. Pengetahuan petugas ditunjukkan kepada penangung jawab P2 ISPA dan petugas MTBS.

Gambaran pengetahuan petugas di puskesmas pammana masih tergolong kurang, ketika mengisi pertanyaan pengetahuan yang diajukan peneliti, masih banyak jawaban yang salah, hanya satu petugas MTBS di puskesmas tersebut berpengetahuan baik, karena di puskesmas sebelumnya petugas tersebut pernah menjadi petugas MTBS. Petugas mempunyai pengetahuan kurang dikarenakan petugas tersebut belum pernah mengikuti pelatihan dan lama kerja sebagai petugas tersebut masih realtif baru. Sehingga pengalaman yang dimilki petugas tersebut masih kurang.

f. Motivasi petugas Menurut pendapat Suryabrata (2000) menyatakan motivasi suatu keadaan dalam diri individu yang mendorong individu untuk melakukan aktivitas-aktivitas tertentu guna mencapai suatu tujuan. Sedangkan menurut Wagito (2002) motivasi adalah kekuatan yang terdapat dalam diri organisme itu bertindak atau berbuat dan dorongan ini biasanya tertuju pada suatu tujuan tertentu. Adapun yang dimaksud dengan motivasi petugas dalam penelitian ini adalah dorongan kerja yang timbul pada diri informan untuk berperilaku dalam pencapaian hasil kerja yang baik. 
Gambaran motivasi petugas di puskesmas pammana diketahui bahwa motivasi yang dimilki penanggung jawab P2 ISPA dan petugas MTBS masih tergolong buruk, hanya satu petugas saja yang mempunyai motivasi baik di puskesmas tersebut. Hal ini mungkin terjadi karena kuranngnya motivasi yang diberikan pimpinan kepada bawahan dalam melaksanakan penemuan kasus pneumonia balita. Karena Motivasi yang di terima kurang, maka target penemuan kasus di puskesmas tersebut tidak tercapai.

6. Kepemimpinan Kepala Puskesmas kepemimpinan adalah hubungan yang tercipta dari adanya pengaruh yang dimilki oleh seseorang terhadap orang lain sehingga orang lain tersebut secara sukarela mau dan bersedia bekerjasama untuk mencapai tujuan yang diinginkan (Terry dalam azwar, 2002). Kepemimpinanan yang ditetapkan oleh seorang pemimpin dalam organisasi dapat menciptakan integrasi yang serasi dan mendorong semangat kerja karyawan untuk mencapai sasaran yang maksimal (Hasibuan, 2001). Dalam penelitian ini yang dimaksud dengan kepemimpinan kepala puskesmas adalah kemampuan kepala puskesmas dalam memimpin dan memberikan dukungan terhadap pelaksanaan program penemuan kasus pneumonia balita di puskesmas.

Berdasarkan informasi dari informan pendukung, kepemimpinan kepala puskesmas masih tergolong tidak baik, hal ini sesuai dengan pengakuan atau jawaban dari kepala puskesmas, terutama dalam hal penyampaian pendapat dan penghargaan yang diberikan pimpinanan kepada petugas yang berprestasi.

7. Ketersediaan sarana dan Prasarana

Sarana adalah salah satu perangkat administrasi, yaitu sesuatu yang dibutuhkan untuk melaksnakan pekerjaan administrasi (Azwar,2002).

Sarana dan prasarana sangat penting dalam kegiatan program penemuan kasus pneumonia balita. Sarana tersebut yang diteliti yaitu media cetak dan media penyuluhan terkait program penemuan pneumonia di puskesmas, yang dinilai berdasarkan observasi peneliti. Adapun media cetak meliputi stempel ISPA, register harian pneumonia, formulir laporan bulanan, buku pedoman pengendalian ISPA, pedoman tatalaksana pneumonia/ MTBS, pedoman autopsi verbal. Sedangkan media penyuluhannya meliputi poster, lefleat pneumonia balita, lembar balik, kit advokasi dan kit pemberdayaan masyarakat, dvd tatalakasana, tv spot dan radio spot terkait pneumonia balita.

Gambaran media cetak dan media penyuluhan di puskesmas Pammana dalam penemuan kasus pneumonoa balita, berdasarkan hasil observasi Puskesmas tersebut, mempunyai register harian pneumonia, formulir laporan bulanan, pedoman tatalaksana pneumonia/MTBS yang terpasang di dinding. Selain itu, untuk media penyuluhannya hanya mempunyai poster pneumonia balita. Sedangkan media lainnya sepeti stempel ISPA, buku pedoman P2 ISPA dan lembar balik pneumonia balita tidak dimiliki oleh puskesmas yang tidak berhasil mencapai target nasional, padahal 180 media tersebut diadakan oleh Dinkes. Hal ini mungkin terjadi, karena adanya pergantian petugas atau penanggung jawab program, akan tetapi terkait media cetak dan media penyuluhan tidak dipindah tangankan ke petugas yang baru. Sehingga media tersebut di puskesmas tidak dapat digunakan untuk program selanjutnya.

Penelitian ini didukung oleh beberapa penelitian yaitu penelitian Warsihayati (2002), Nurcik (2002) dan Sinora (2005) menyatakan bahwa, ada hubungan yang bermakna antara ketersediaan barang cetakan pada Puskesmas pelaksna MTBS dengan penemuan penderita penumonia di Kabupaten Cianjur. Selain itu penelitian ini juga sejalan dengan penelitian Hidayati dan Wahyono (2011) menunjukkan adanya hubungan yang bermakana antara sarana dan prasarana pendukung MTBS dengan kejadian pneumonia.

8. Kegiatan Evaluasi

Kegiatan evaluasi adalah suatu proses untuk menyediakan informasi mengenai sejauh mana suatu kegiatan 
tertentu telah tercapai, bagaimana perbedaan pencapaian yang dilakukan dengan suatu standar tertentu, untuk mengetahui apakah ada selisih diantara keduanya, serta bagaimana manfaat yang telah dikerjakan itu dibandingkan dengan harapanharapan yang ingin diperoleh (Umar, 2002)

Gambaran kegiatan evaluasi di puskesmas Pammana dalam penemuan kasus pneumonia balita, dilakukan setiap bulan, seperti Lokmin dan pra lokmin, karena kegiatan tersebut sudah ditetapkan oleh Dinkes, sehingga semua puskesmas melakukan kegiatan tersebut. Adapun yang dibahas dalam evaluasi yaitu pencapaian hasil program, permasalahan atau kendala yang dihadapi, seperti kurang ditemukannya kasus pneumonia balita di puskesmas tersebut..

Hasil penelitian ini sesuai dengan penelitian Warsihayati (2002) menunjukkan bahwa kegiatan evaluasi di puskesmas tidak memberikan pengaruh terhadap cakupan penemuan kasus pneumonia balita. Hal ini terjadi karena semua puskesmas setiap bulannya melakukan evaluasi program untuk melihat sejauh mana tujuan dari program dapat tercapai. Menurut informan ahli kegiatan evaluasi juga berfungsi sebagai pembangun motivasi petugas dalam bekerja, sehingga kegiatan evaluasi harus selalu dilakukan oleh puskesmas. Dengan demikian, seharusnya setiap program melakukan kegiatan evaluasi, karena pada saat evaluasi yang dilakukan setiap bulan tidak semua program puskesmas dibahas.

\section{KESIMPULAN}

a. Penyusunan rencana program penemuan kasus pneumonia balita tahun 2017 - 2019 di Puskesmas Pammana dibuat pada awal setiap tahunnya. Sehingga perencanaannya dibuat pada saat awal tahun pelaksanaan program.

b. Kegiatan program penemuan kasus pneumonia balita di puskesmas Pammana hanya melakukan pelayanan medis di puskesmas dan penyuluhan di Posyandu, sehingga penemuan kasus pneumonia tidak mencapai target.

c. Puskesmas Pammana tidak mendapatkan laporan kasus dari klinik swasta yang ada di wilayah kerja puskesmas.

d. Puskesmas Pammana belum mempunyai tenaga terlatih, sehingga petugas belum mengetahui dan memahami pneumonia balita secara menyeluruh.

e. Penanggung jawab P2 ISPA dan MTBS di puskesmas Pammana baru bekerja 1-2 tahun, sehingga masih relatif baru dan belum mempunyai pengalaman dan wawasan yang luas dalam menjalankan program tersebut.

f. Pengetahuan penanggung jawab P2 ISPA di puskesmas Pammana masih tergolong Kurang, petugas belum memahami konsep pneumonia balita.

g. Motivasi yang dimilki petugas di puskesmas Pammana masih tergolong kurang, motivasi mempengaruhi petugas dalam bekerja.

h. Kepemimpinan kepala puskesmas di puskesmas Pammana berdasarkan penilaian petugasnya masih tergolong kurang, khususnya dalam hal pengambilan keputusan.

i. Ketersediaan media cetak dan media penyuluhan di puskesmas Pammana berdasarkan observasi puskesmas tersebut tidak mempunyai stempel ISPA, buku pedoman pengendalian ISPA, lembar balik pneumonia, padahal media ini dimiliki oleh puskesmas yang berhasil mencapai target.

\section{SARAN}

Dari hasil penelitian yang dilakukan di Puskesmas Pammana, maka ada beberapa saran yang dapat di sampaikan:

1. Bagi Dinas Kesehatan
a. Sebaiknya Dinas Kesehatan
Kabupaten Wajo mewajibkan
penangung jawab P2 ISPA di puskesmas untuk melakukan perencanaan setiap tahunnya dan merealisasikan perencanaan tersebut.
b. Melaksanakan kegiatan surveilans pasif dan aktif berbasis Puskesmas di Kabupaten Wajo agar dapat membuat perencanaan yang evidence base.
c. Menggerakkan kader kesehatan di setiap Puskesmas, sehingga 
kegiatan deteksi dini di masyarakat dapat dilaksanakan.

d. Disarankan untuk meningkatkan pembinaan dan pelatihan kepada penanngung jawab P2 ISPA mengenai pengetahuan dasar tentang pneumonia balita, sehingga tenaga kesehatan di Puskesmas mengetahui konsep dasar pneumonia balita.

e. Menjalin kerjasama dengan sektor lain dan melakukan advokasi ke pemangku kebijakan dalam penemuan kasus pneumonia balita, seperti bekerjasama dengan BLHD, Badan Pemberdayaan Perempuan.

\section{Bagi Puskesmas}

a. Sebaiknya perlu melaksanakan penemuan kasus secara aktif dan menggerakkan kader di tiap wilayah agar cakupan penemuan kasus dapat meningkat.

b. Melaksanakan kegiatan surveilans berbasis Puskesmas secara komprehensip, agar perencanaan dan evaluasi yang dibuat berdasarkan evidence base.

c. Melakukan kegiatan deteksi dini atau penjaringan kasus pneumonia balita di masyarakat dan bekerjasama dengan kader, sehingga penemuan kasus pneumonia balita di puskesmas dapat mencapai target nasional.

d. Menjalin kerjasama dengan sektor lain dalam hal penemuan kasus pneumonia balita, seperti bekerjasama dengan kelurahan, kecamatan, LSM.

e. Selain itu perlu diadakan sharing atau berbagi pengalaman dengan petugas lain dalam menjalankan program puskesmas, sehingga kegiatan penemuan kasus pneumonia balita dapat dilaksanakan secara bersamasama dengan semua petugas puskesmas.

f. Serta disarankan memberikan penghargaan berupa predikat petugas terbaik setiap bulan atau setiap tahun sekali, untuk meningkatkan motivasi petugas dalam pekejaanya.
DAFTAR PUSTAKA

Adnan, Dewi Sartika. 2013. Evaluasi pelaksanaan Manajemen Terpadu Balita Sakit (MTBS) pada Petugas Kesehatan dalam Tatalaksana Pneumonia Pada Balita di Kabupaten Aceh Besar. Tesis Pasca Sarjana UGM. Yogyakarta.

Agusman, 2001. Faktor-faktorkan yang berhubungan dengan cakupan penemuan oenderita pneumonia pada Puskesmas di Kota Palembang tahun 2000. Tesis FKM UI, depok.

Azwar azrul, 2002, Menjaga Mutu Pelayanan Kesehatan. Pustaka Sinar Harapan, Jakarta.

Departemen Kesehatan RI. 2003. Pedoman Pengelolaan Kesehatan di Kelompok Usia Lanjut. Jakarta: Departemen Kesehatan.

2004. Keputusan Menteri Kesehatan Republik Indonesia Nomor 128/MENKES/SK/II/2004 Tentang Kebijakan Dasar Pusat Kesehatan Masyarakat. Jakarta: Departemen Kesehatan. 2008, Modul MTBS Revisi tahun 2008. Derani M, Pope D, Mascarenchas, Smith KR, Weber M, Nigel B. 2008. Indoor air polution from unprocessed solid fuel use and pneumonia risk in children aged under five years; a systematic review and meta analysis. Bull WHO: 86:390398.

Dharoh, Ana dkk. 2013. Faktor-Faktor Yang Berhubungan Dengan Cakupan Penemuan Penderita Pneumonia Pada Balita Di Kota Semarang. Jurnal Kesehatan Masyarakat UDINUS: Semarang.

Marlinawati L S. 2015. Faktor-Faktor yang mempengaruhi Kasus Pneumonia Balita di puskesmas Kota Tanggerang Selatan Tahun 2015. Skripsi. Universitas Islam Negeri Syarif Hidayatullah: jakarta.

Paramita R.2011. Gambaran Kegiatan Penemuan Kasus Pneumonia Pada Balita di Puskesmas Se-Kota Semarang Tahun 2011. Jurnal Kesehatan Masyarakat. Universitas Diponegoro:Semarang. 
Tabel 1.

Distribusi Frekuensi Penderita Pneumonia pada bayi/balita Menurut Waktu di Wilayah Kerja UPTD Puskesmas Pammana Tahun 2017-2019

\begin{tabular}{|c|c|c|c|c|c|c|c|c|}
\hline \multirow{3}{*}{ Bulan } & \multicolumn{8}{|c|}{ Kejadian Pneumonia } \\
\hline & \multicolumn{2}{|c|}{2017} & \multicolumn{2}{|c|}{2018} & \multicolumn{2}{|c|}{2019} & \multicolumn{2}{|c|}{ Total } \\
\hline & $\mathbf{N}$ & $\%$ & $\mathbf{N}$ & $\%$ & $\mathbf{N}$ & $\%$ & $\mathbf{N}$ & $\%$ \\
\hline Januari & 0 & 0 & 1 & 4.8 & $\overline{1}$ & 10 & 2 & 5.3 \\
\hline Februari & 0 & 0 & 0 & 0 & 4 & 40 & 4 & 10.5 \\
\hline Maret & 0 & 0 & 0 & 0 & 0 & 0 & 0 & 0 \\
\hline April & 0 & 0 & 0 & 0 & 0 & 0 & 0 & 0 \\
\hline Mei & 1 & 14.3 & 2 & 9.5 & 0 & 0 & 3 & 7.9 \\
\hline Juni & 2 & 28.6 & 0 & 0 & 0 & 0 & 2 & 5.3 \\
\hline Juli & 2 & 28.6 & 2 & 9.5 & 0 & 0 & 4 & 10.5 \\
\hline Agustus & 1 & 14.3 & 5 & 23.8 & 5 & 50 & 11 & 28.9 \\
\hline September & 1 & 14.3 & 3 & 14.3 & 0 & 0 & 4 & 10.5 \\
\hline Oktober & 0 & 0 & 4 & 19.0 & 0 & 0 & 4 & 10.5 \\
\hline November & 0 & 0 & 4 & 19.0 & 0 & 0 & 4 & 10.5 \\
\hline Desember & 0 & 0 & 0 & 0 & 0 & 0 & 0 & 0 \\
\hline Total & 7 & 100 & 21 & 100 & 10 & 100 & 38 & 100 \\
\hline
\end{tabular}

Tabel 2

Distribusi Frekuensi Penderita Pneumonia pada Bayi/Balita Menurut Kelompok Umur di Wilayah Kerja UPTD Puskesmas Pammana Periode 2017-2019

\begin{tabular}{|c|c|c|c|c|c|c|c|c|}
\hline \multirow{3}{*}{$\begin{array}{l}\text { Kelompok } \\
\text { Umur } \\
\text { (Tahun) }\end{array}$} & \multicolumn{6}{|c|}{ Kejadian Pneumonia } & \multirow{2}{*}{\multicolumn{2}{|c|}{ Total }} \\
\hline & \multicolumn{2}{|c|}{2017} & \multicolumn{2}{|c|}{2018} & \multicolumn{2}{|c|}{2019} & & \\
\hline & $\mathbf{N}$ & $\%$ & $\mathbf{N}$ & $\%$ & $\mathbf{N}$ & $\%$ & $\mathbf{N}$ & $\%$ \\
\hline$<1$ & 5 & 71,4 & 12 & 57,1 & 9 & 90 & 26 & 68,4 \\
\hline $1-5$ & 2 & 28,6 & 9 & 42,9 & 1 & 10 & 12 & 31,6 \\
\hline Total & 7 & 100 & 21 & 100 & 10 & 100 & 38 & 100 \\
\hline
\end{tabular}

Sumber : Data Sekunder

Tabel 3

Distribusi Frekuensi Penderita Pneumonia pada Bayi/Balita Menurut Jenis Kelamin di Wilayah Kerja UPTD Puskesmas Pammana Periode 2017-2019

\begin{tabular}{|c|c|c|c|c|c|c|c|c|}
\hline \multirow{3}{*}{$\begin{array}{l}\text { Kelompok } \\
\text { Umur } \\
\text { (Tahun) }\end{array}$} & \multicolumn{6}{|c|}{ Kejadian Pneumonia } & \multirow{2}{*}{\multicolumn{2}{|c|}{ Total }} \\
\hline & \multicolumn{2}{|c|}{2017} & \multicolumn{2}{|c|}{2018} & \multicolumn{2}{|c|}{2019} & & \\
\hline & $\mathbf{N}$ & $\%$ & $\mathbf{N}$ & $\%$ & $\mathbf{N}$ & $\%$ & $\mathbf{N}$ & $\%$ \\
\hline Laki-Laki & 2 & 28,6 & 7 & $\overline{33,3}$ & 5 & 50 & 14 & $\overline{36,8}$ \\
\hline Perempuan & 5 & 71,4 & 14 & 66,7 & 5 & 50 & 24 & 63,2 \\
\hline Total & 7 & 100 & 21 & 100 & 10 & 100 & 38 & 100 \\
\hline
\end{tabular}




\section{Tabel 4}

Distribusi Frekuensi Penderita Pneumonia pada bayi/Balita Menurut Tempat di Wilayah Kerja UPTD Puskesmas Pammana Tahun 2017-2019

\begin{tabular}{|c|c|c|c|c|c|c|c|c|}
\hline \multirow{3}{*}{ Bulan } & \multicolumn{8}{|c|}{ Kejadian Pneumonia } \\
\hline & \multicolumn{2}{|c|}{2017} & \multicolumn{2}{|c|}{2018} & \multicolumn{2}{|c|}{2019} & \multicolumn{2}{|c|}{ Total } \\
\hline & $\mathbf{N}$ & $\%$ & $\mathbf{N}$ & $\%$ & $\mathbf{N}$ & $\%$ & $\mathbf{N}$ & $\%$ \\
\hline Kel. Cina & 0 & 0 & 6 & 28.6 & 3 & 30 & 9 & 23.7 \\
\hline Kel.Pammana & 1 & 14.3 & 0 & 0 & 0 & 0 & 1 & 2.6 \\
\hline Desa Kampiri & 1 & 14.3 & 0 & 0 & 1 & 10 & 2 & 5.3 \\
\hline Desa Pallawarukka & 1 & 14.3 & 4 & 19.0 & 4 & 40 & 9 & 23.7 \\
\hline Desa Watampanua & 2 & 28.6 & 5 & 23.8 & 1 & 10 & 8 & 21.1 \\
\hline Desa Lapaukke & 0 & 0 & 0 & 0 & 0 & 0 & 0 & 0 \\
\hline Desa Tobatang & 0 & 0 & 0 & 0 & 0 & 0 & 0 & 0 \\
\hline Desa Tadang Palie & 1 & 14.3 & 2 & 9.5 & 0 & 0 & 3 & 7.9 \\
\hline Desa Lagosi & 1 & 14.3 & 1 & 4.8 & 0 & 0 & 2 & 5.3 \\
\hline Desa Tr.Tengnga & 0 & 0 & 0 & 0 & 0 & 0 & 0 & 0 \\
\hline RS/Suber Lain & 0 & 0 & 3 & 14.3 & 1 & 10 & 4 & 10.5 \\
\hline Total & 7 & 100 & 21 & 100 & 10 & 100 & 38 & 100 \\
\hline
\end{tabular}

Sumber : Data Sekunder 